\title{
Study on Mechanical Properties of Epoxy Polymer Reinforced with NanoSiC particles
}

\author{
Amal Nassar, Eman Nassar \\ Department of Mechanical Engineering, Higher Technological Institute, Tenth of Ramadan City, Egypt \\ *Corresponding Author: eman.nasser@hti.edu.eg
}

Copyright (C) 2013 Horizon Research Publishing All rights reserved.

\begin{abstract}
In this paper we study the effect of NanoSiC particles on the mechanical properties for the polymer composite material. We using the epoxy resin (EPOBOND Epoxy) supplied from epobond for chemicals and electrical components in Egypt as matrix reinforced with silicon carbide nanoparticles with different weight percentage $(5,10$, 15 and 20). The tensile tests were made by using LLOYD" Universal Tensile Testing Machine System at room temperature, the wear tests were made by Pin-on-Disc machine and A Charpy impact test machine was used for measuring the impact toughness during impact testing. It is found that the addition of NanoSiC particles on epoxy resin can improve the wear resistance however the strength decrease with further increase in weight percentage of reinforcement.
\end{abstract}

Keywords Silicon Carbide ,Mechanical Properties , Polymer Matrix and Nanoparticles

\section{Introduction}

Epoxy resin has been widely used in the industrial and aerospace field, as fiber-reinforced composite matrix and adhesive. Epoxy is both the basic component and the cured end product of it, as well as a colloquial name for the epoxide functional group. It , also known as polyepoxides are a class of reactive prepolymers and polymers which contain epoxide groups. It may be reacted (cross-linked) either with themselves through catalytic homo polymerization, or with a wide range of co-reactants including poly functional amines, acids (and acid anhydrides), phenols, alcohols, and thiols. These co-reactants are often referred to as hardeners or curatives, and the cross-linking reaction is commonly referred to as curing. [1]

To improve epoxy resin properties, a common method is introducing particles in the resin, including liquid rubbers, thermoplastics, copolymers, silica nanoparticles, silicate layers, core shell particles, and combinations of these. The major toughening mechanisms involve rubber particle deboning/cavitation, localized shear banding of matrix as well as rubber particle bridging. Fracture toughness of rubber toughened epoxy resin will be improved obviously, while many other desirable properties, such as elastic modulus and failure strength, will decrease significantly [2]. In comparison, rigid Nano fillers can improve the fracture toughness, stiffness, andeven strength of epoxy resin [3-7].

Andritsch et al. [8] prepared Nano composites filled with $\mathrm{SiO} 2, \mathrm{Al} 2 \mathrm{O} 3$, and AIN with an average particles size from $22 \mathrm{~nm}$ to $10 \mathrm{~nm}$ and studied the nanoparticles dispersion and DC breakdown strength. They observed the highest DC breakdown strength for $0.5 \mathrm{wt} . \%$ for two component system. It was also noticed that the DC breakdown strength increased with $10 \mathrm{wt} . \%$ as compared to 2 and $5 \mathrm{wt} . \%$ and again decreased with $15 \mathrm{wt} \% \%$ Nano-fillers. Yasmin et al. [9] studied the dispersion of clay nanoparticles in epoxy-based composites using a three roll mill with the concentration of 1-10 wt.\%. This technique was found highly efficient and environmentally friendly due to excellent dispersion of nanoparticles within a short time. Elastic modulus was improved up to $80 \%$ with $10 \mathrm{wt} . \%$ addition of clay nanoparticles in epoxy. Absence of any improvement in tensile strength of the Nano composites over pure epoxy was due to the clustering of nanoparticles and/or to the occasional occurrence of Nano- to micro size voids in the microstructure. Li et al. [10] prepared the Epoxy Nano composites with exfoliated nano clay and a novel ultrafine full-vulcanized powdered rubber. The morphology of the epoxy/rubber/clay Nano composite has been studied using $\mathrm{X}$-ray diffraction (XRD) and transmission electron microscopy (TEM). Their study showed that the unmodified clay was fully exfoliated and uniformly dispersed in the resulting Nano composites and found that the impact strength of this special epoxy/rubber/clay Nano composite increased up $107 \%$ over the neat epoxy resin. Thermal analyses showed that thermal stability of the Nano composites was much better than that of epoxy Nano composites based on organically modified clay. Damian et al. [11] synthesized epoxy-based Nano composites s reinforced with multi walled carbon Nano-tubes (MWNT). They functionalized MWNTs in order to increase the dispersion in 
the polymer matrix and thus to ensure good adhesion between the two components. Their study showed that the structure of amine MWNT-B100 exhibit compatibility with the epoxy matrix. However, the higher thermo stability was achieved by the composite based on MWNTCOOH as observed from TGA. Frache et al. [12] prepared the epoxy based Nano composites s reinforced with home-made hydrotalcites (HTlc) and montmorillonite-(MMT-) type layered silicates and studied the morphology, dispersion and thermal analysis of the Nano composites s. Their research showed possibility to obtain Nano-structured materials, characterized by the resin intercalation into HTlc galleries, by using a proper exchange of the pristine hydrotalcite with stearate anions. The thermal analysis indicated that Nano composites s based on HTlc were prone to decompose, both in air and nitrogen, while in the case of the Nano composites based on the organophilic MMT a slight improvement was found in air. Jordan et al. [13] studied the effect of addition of micron and Nano sized silica inclusions on polyurethane matrix and found it as an increment in density as the filler content increased. He investigated that the composite density further can be increased with micron-sized inclusions as compared to the density for the Nano sized inclusions. In above studies, no body tried to utilize silica sand nanoparticles as reinforcement agents in epoxy based composites. Exclusively, the objective of present research is to fill this gap and study the effect of addition of silica sand nanoparticles on epoxy based composites.

\section{Experimental}

The ceramic was received in the form of powder from "SABI" company. it was washed with water to remove any Impurities particles followed by drying it in an oven at 300 , $\mathrm{SiC}$ was ground to nanoparticles using dry ball milling with zirconia balls as grinding media with different steps of sieve analysis. This high-energy milling was known as one of the "top-down" nanoparticles type approach, which generally relies on physical methods for their production.

Epoxy resin (EPOBOND Epoxy) supplied from epobond for chemicals and electrical components in Egypt. Viscosity at $25^{\circ} \mathrm{C}$ is $2475 \mathrm{mPa} \cdot \mathrm{s}$. The average particle radius of spherical $\mathrm{SiC}$ nanoparticles was $25 \mathrm{~nm}$. Before mixing with epoxy resin (EPOBOND Epoxy), $\mathrm{SiC}$ nanoparticles were dried at $120{ }^{\circ} \mathrm{C}$ to remove any moisture for 6 hours. SiC Nanoparticles were mixed with epoxy using stirrer for 3 hours at room temperature figure 1 shows the apparatus used for preparing the this mixtures. After that, the hardener (poly-amino)was added to the mixtures in a ratio of $50: 25$, while stirring slowly. The mixture was poured into molds made of Teflon formed according to the American Society for Testing and Materials standard (ASTM) Figure (2). Tensile tests were made at room temperature by "LLOYD" Universal Tensile Testing Machine System having a capacity of $150 \mathrm{KN}$. The wear test was performed on Pin-on-Disc apparatus shown in figure (3). In this test the flat end of cylindrical specimen $8 \mathrm{~mm}$ in diameter and $12 \mathrm{~mm}$ length was fixed in chuck jaws to prevent specimens from rotation during the test. Axial load was applied to the pins against the plane surface of the rotating disc. Each specimen was weighed before the experiment and after it by a digital balance having sensitivity of $0.001 \mathrm{gm}$. The duration of the experiment was controlled by stopwatch. The average value of the weight loss percentage as a function of test time was calculated. From weight loss of the specimens $(\Delta \mathrm{m})$ it is possible to evaluate a dimensionless parameter known as $\mathrm{w}$, "wear rate" define as [14]:

$$
\mathrm{W}=\frac{\Delta \mathrm{m}}{\rho \times v \times t \times A}
$$

Where:

$\Delta \mathrm{m}=$ weight loss (gm), $\rho=$ average density of Metal Matrix Composite, $\mathrm{t}=$ test time (s)

$v=$ velocity $(\mathrm{mm} / \mathrm{s}), \mathrm{A}=$ apparent contact area $\left(\mathrm{mm}^{2}\right)$

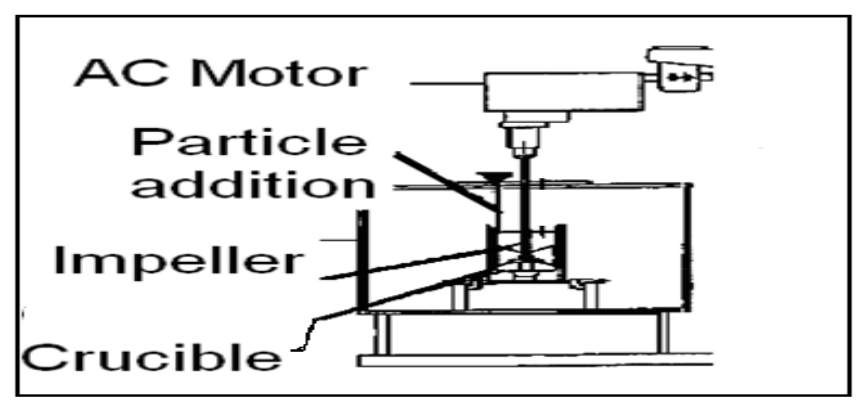

Figure 1. the apparatus used for preparing the mixtures

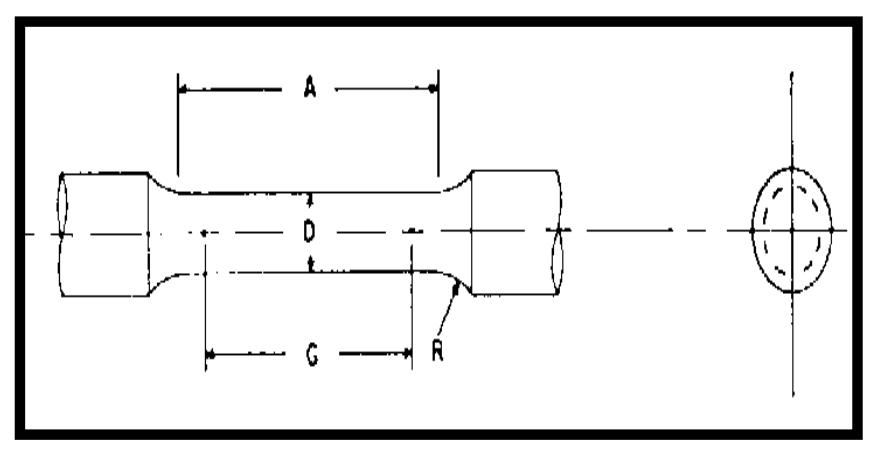

$\mathrm{G}$ - Gage length $=12,5 \pm 0.1 \mathrm{~mm} \mathrm{R}$ - Radius of fillet $=6 \mathrm{~mm}$

$\mathrm{D}$-Diameter $=3.0 \pm 0.1 \mathrm{~mm} \mathrm{~A}$ - Length of reduced section $=36 \mathrm{~mm}$

Figure 2. The standard tensile specimen.

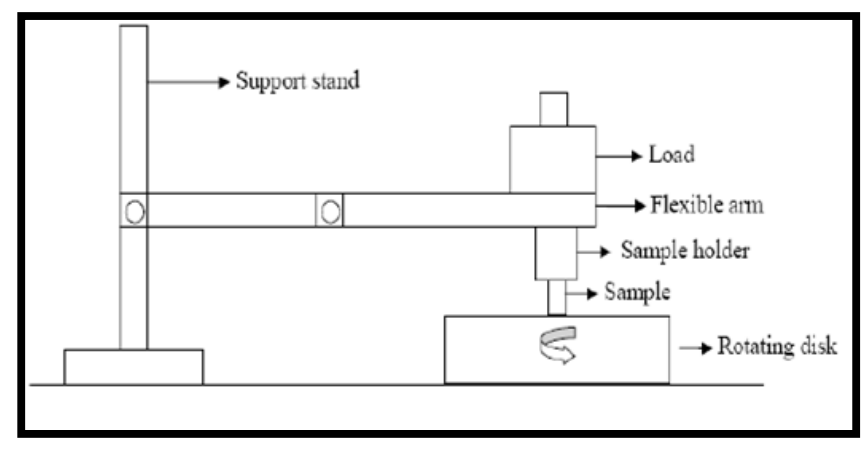

Figure 3. Pin-on disc wear test 
A charpy impact test machine figure (4) was used for measuring the absorbed energy of the samples as impact toughness during impact testing. All tests were carried out at room temperature. Impact toughness test pieces were cut from the billets. The standard charpy specimens, $10 \times 10 \times$ $55 \mathrm{~mm}$, with a $2 \mathrm{~mm} \mathrm{~V}$-notch were prepared.

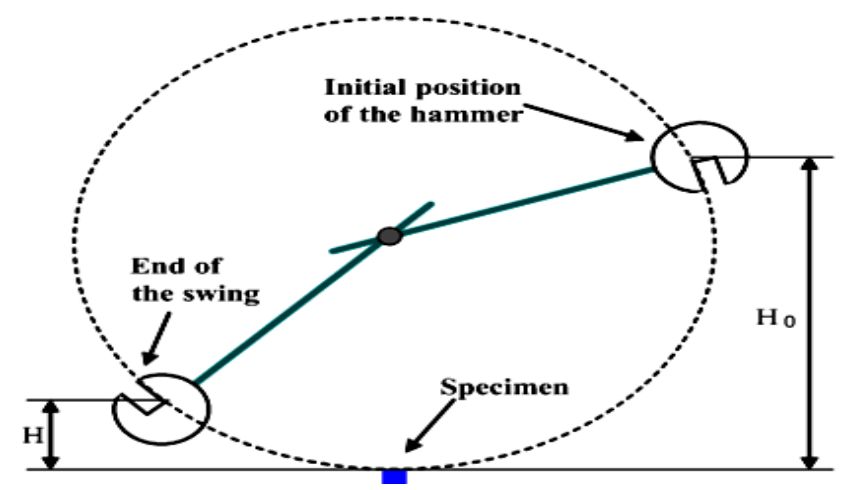

Figure 4. Charpy Impact Test [15]

\section{Results and Discussion}

\subsection{Characterization of the Epoxy-SiC Nanoparticles Composites}

\subsubsection{Density and Specific gravity determination of Nanoparticles Composites. Silicon carbide}

Nanoparticles being denser as compared to epoxy may cause an enhancement in density of epoxy when added as reinforcement as shown in Figure 5. The sic nanoparticles when added to polymer tended to create a linkage of bonding between nanoparticles and polymer which some time results in higher density of the composites. The method used for measuring the density is based on Archimeds Law.

$$
\mathrm{V}_{\mathrm{L}}=\mathrm{W}_{\mathrm{A}}-\mathrm{W}_{\mathrm{L}} / \rho
$$

Where:

$\mathrm{V}_{\mathrm{L}}$ : the volume of liquid displacement by sample $; \mathrm{W}_{\mathrm{A}}$ : the weight of the sample in air; $\mathrm{W}_{\mathrm{L}}$ : the weight of the sample in liquid $; \rho$ : the density of liquid

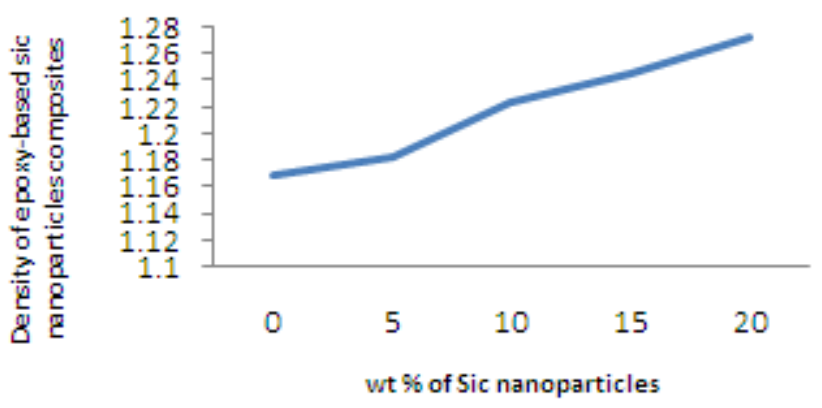

Figure 5. Density of epoxy-Sic composites

3.2.2. Mechanical Properties

\subsubsection{Evaluation of the Tensile Properties}

The properties of the composites depend upon the method of dispersion of particles, aggregation of particles, and interaction between particles and polymers. The thickness and density of the interphase developed between two constituents depends on the interaction between particles and polymer [13]. Inter particle distance also plays an important role in the interphase behavior and properties of the composites. Tensile properties of the composites are mostly affected by the materials, method, specimen condition and preparation, and also by percentage of the reinforcement [16].

The results of the tensile tests of the composite at different weight percentages of $\mathrm{SiC}$ nanoparticles, at room temperature are illustrated in figures (5). Figure shows that the strength decrease with further increase in weight percentage of reinforcement. This could be due to the weak bonding between the matrix and the nanoparticles. It is apparent that there are two factors influencing the tensile strength of the composite:

1. The reinforcing particles serve to increase the strength of the material by simple load transfer, which is dependent on the bond integrity at the particle/matrix interface and by retarding dislocation motion.

2. The inhibition of plastic relaxation at the particle/matrix interface.

The results show that the addition of $\mathrm{SiC}$ Nanoparticles to epoxy cause a drop in the strength of the alloy at room temperature continuously as the $\mathrm{SiC}$ Nanoparticles increase from 10 to $20 \mathrm{wt} . \%$ as the strength decreases with further increase in the weight percentage of the reinforcement.

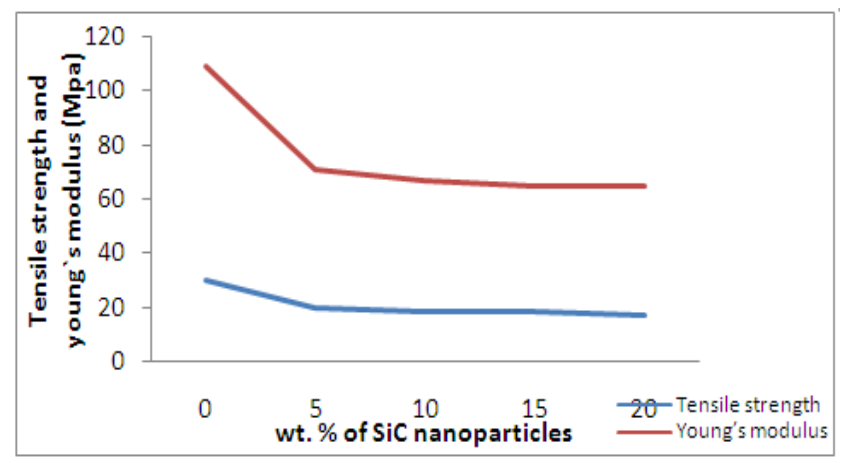

Figure 6. Tensile strength and Young's modulus of epoxy reinforced with SiC Nanoparticles

\subsubsection{Wear Behaviour of the Composite Material}

The wear test reported is the average of two readings. Figures (7) shows the wear rate of the investigation specimens. The wear rates are plotted as a function of applied pressure. The wear results show that the reinforced specimens have better wear resistance than the unreinforced specimens. It is clear from figure that silicon carbide nanoparticles enhanced the wear resistance of unreinforced epoxy. The wear rate decrease from $5.8\left(\times 10^{-6} \mathrm{~g} / \mathrm{m}\right)$ to 3.3 $\left(\times 10^{-6} \mathrm{~g} / \mathrm{m}\right)$ at applied pressure equal to $1 \mathrm{MPa}$. Also, the 
wear rate decreases from $7.23\left(\times 10^{-6} \mathrm{~g} / \mathrm{m}\right)$ to $8.69\left(\times 10^{-6} \mathrm{~g} / \mathrm{m}\right)$ as the weight percentage of $\mathrm{SiC}$ increases from 10 to $20 \mathrm{wt} . \%$ at applied pressure equal to $3 \mathrm{MPa}$. This is probably due to the fact that epoxy can easily remove at sliding surfaces (contact area) but in the composite case the ceramic Nano particles act as a rough surface relative to the counterface against which they slide.

Figure (7) reveal that increasing the applied pressure increases wear rate of all investigated specimens, at room temperature the conditions of wear are seems to be mild wear. The ' mild wear ' conditions are distinguished by low wear rate. The sever wear conditions were clearly seen. The noticed trend is consistent with that noticed by many investigators [18-2]. They suggest that the wear rate increase gradually with applied load in the mild wear region. However, at a 'critical load' that depends on sliding velocity, the wear rate abruptly increases to reflect the condition termed 'severe' wear.

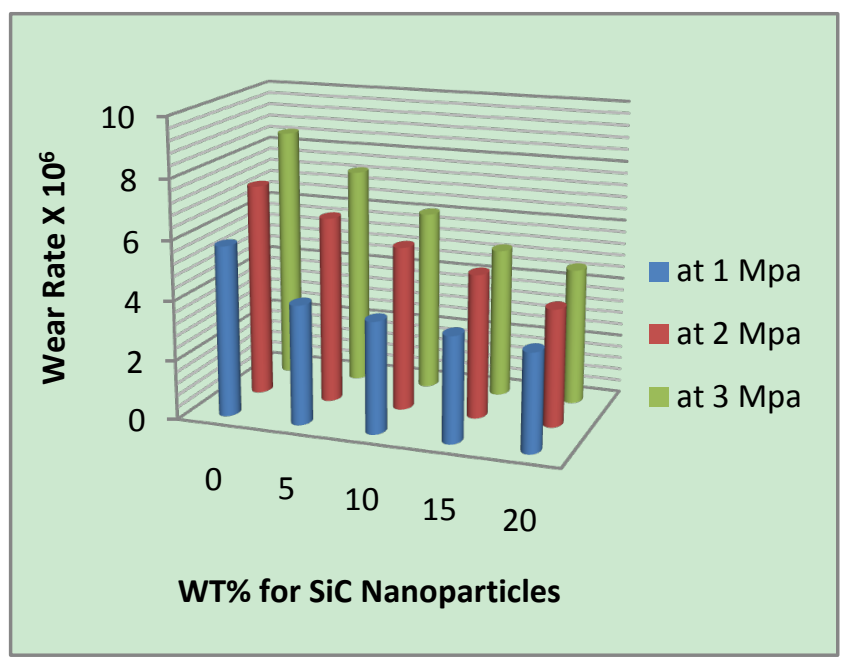

Figure 7. wear rate of epoxy reinforced with $\mathrm{SiC}$ Nanoparticles

\section{Conclusions}

In this paper, mechanical properties of epoxy reinforced with different weight percent of silicon carbide nanoparticles were investigated. The experimental results indicate that the strength decrease with further increase in weight percentage of reinforcement. This could be due to the weak bonding between the matrix and the nanoparticles. The wear results show that Nano particles enhanced the wear resistance of unreinforced epoxy these is due to the ceramic Nano particles act as a rough surface relative to the counterface against which they slide.

\section{REFERENCES}

[1] M. A. Marciano, R. Ordinola-Zapata, T. V. R. N. Cunha, M. A. H. Duarte, B. C. Cavenago, R. B. Garcia, C. M. Bramante,
N. Bernardineli, I. G. Moraes "Analysis of four gutta-percha techniques used to fill mesial root canals of mandibular molars". International Endodontic Journal 44. April 2011, pp 321-329.

[2] M.Jun,M.S.Mo,X.S.Du,S.R.Dai,andI.Luck,"Studyof epoxy toughened by in situ formed rubber nanoparticles," Journal ofApplied Polymer Science,vol.110,no.1,pp.304-312,2008.

[3] J. Ma, M.-S.Mo, X.-S. Du, P. Rosso, K. Friedrich, and H.C. Kuan, "Effect of inorganic nanoparticles on mechanical property, fracture toughness and toughening mechanism of two epoxy systems," Polymer, vol. 49, no. 16, pp. 3510-3523, 2008.

[4] L.-C.Tang,H.Zhang,S.Sprenger,L.Ye,andZ.Zhang, "Fracture mechanisms of epoxy-based ternary composites filled with rigid-soft particles," Composites Science and Technology,vol. 72, pp. 558-565, 2012.

[5] S. Deng, J. Zhang, L. Ye, and J. Wu, "Toughening epoxies with Halloysite nanotubes,"

Polymer,vol.49,no.23,pp .5119-5127, 2008.

[6] S. Zhao, L. S. Schadler, H. Hillborg, and T. Auletta, "Improvements and mechanisms of fracture and fatigue properties of well-dispersed alumina/epoxy Nano composites s," CompositesScience and Technology, vol. 68, no. 14, pp. 2976-2982, 2008.

[7] [7]T.H.Hsieh,A.J.Kinloch,K.Masania,J.SohnLee,A.C. Taylor, and S. Sprenger, "The toughness of epoxy polymers and fiber composites modified with rubber microparticles and silica nanoparticles," Journal of Materials Science ,vol. 45, no. 5, pp. 1193-1210, 2010.

[8] T. Andritsch, R. Kochetov, Y. T. Gebrekiros, U. Lafont, P. H. F. Morshuis, and J. J. Smit, "Synthesis and dielectric properties of epoxy based Nano composites s," in Proceedings of the Annual Report Conference on Electrical Insulation and Dielectric Phenomena (CEIDP '09), pp. 523-526, 2009.

[9] A. Yasmin, J. L. Abot, and I. M. Daniel, "Processing of clay/ epoxy Nano composites s by shear mixing," ScriptaMaterialia, vol. 49, no. 1, pp. 81-86, 2003.

[10] B. Li, X. Zhang, J. Gao et al., "Epoxy based Nano composites $\mathrm{S}$ with fully exfoliated unmodited clay: mechanical and thermal properties," Journal of Nanoscience and Nanotechnology, vol. 10,no. 9, pp. 5864-5868, 2010.

[11] C. M. Damian, A. M. Pandele, C. Andronescu, A. Ghebaur, S. A. Garea, and H. Iovu, "Epoxy-based Nano composites s rein- forced with new amino functionalized multi-walled carbonnanotubes," Fullerenes Nanotubes and Carbon Nanostructures, vol. 19, no. 3, pp. 197-209, 2011.

[12] A. Frache, O. Monticelli, M. Nocchetti, G. Tartaglione, and U. Costantino, "thermal properties of epoxy resin Nano composites s based on hydrotalcites," Polymer Degradation and Stability, vol. 96, no. 1, pp. 164-169, 2011.

[13] J. Jordan, K. I. Jacob, R. Tannenbaum, M. A. Sharaf, and I. Jasiuk, "Experimental trends in polymer Nano composites s-a review,"Materials Science and Engineering A, vol. 393, no. 1-2, pp. 1-11, 2005.

[14] abd El-halim a. El-akabawy "mechanical properties of A356 /Particle metal matrix composites". Ph.D thesis, ZagazigUniveristyShoubra Faculty of Engineering .pp.78 
1997.

[15] Standard Test Methods for Determining the Charpy Impact Resistance of Notched Specimens of Plastics", ASTM International, United States. pp. 5-7

[16] American Standard of Testing Material (ASTM), Standard Test Method for Tensile Properties of Reinforced thermosetting Plastics Using Straight Sided Specimens, ASTM International, West Conshohocken, Pa, USA,pp 32-37, 2004.

[17] Y.Zheng,K.Chonung,G.Wang,P.Wei,andP.Jiang, "Epoxy/nano-silica composites: curing kinetics, glass transition temperatures, dielectric, and thermal-mechanical performances," Journal of Applied Polymer Science, vol. 111, no. 2, pp. 917-927, 2009.

[18] HakGu Lee, Hui Yun Hwang, \& Dai Gil Lee," Effect of Wear Debris on theTribological Characteristics of carbon fiber epoxy composites", Wear 261,Elsevier, pp. 22-24, 2006.

[19] B. Suresha, G. Chandramohan, P. Samapthkumaran, S.
Seetharamu and S.Vynatheya, "Friction and Wear Characteristics of Carbon-Epoxy and GlassEpoxy Woven Roving Fiber Composites", Journal of Reinforced Plastics andComposites, Volume 25, No. 7, pp. 30-32, 2006.

[20] J. Quintelier, P. Samyn, W. Van Paepegem, P. De Baets, J. Vermeulen, T.Tuzolana and F. Van den Abeele, "Wear Behavior of Carbon Fiber ReinforcedPoly Phenylene Sulfide", Journal of Polymer Composites, Volume 27, No. 1, pp. 52-54, 2006.

[21] N.S.M. El-Tayeb and B.F. Yousif, "Evaluation of Glass Fiber Reinforced Polyester Composite for Multi-Pass Abrasive Wear Applications", Journal ofWear, Volume 262, Issue 9-10, April, pp. 16-18, 2007.

[22] K.H. Zum-Gahr, "Abrasive Wear of Two-Phase Metallic Materials with aCoarse Microstructure", International Conference on Wear of Materials,American Society of Material Engineering, Vancouver, pp. 44-46, 1985.

[23] A.A. Reda, R. Bowden and V.C. Westclot," Characteristics of Particles Generated at the Interface Between Sliding Surface", Wear, Vol.34, pp. 56-59, 1975. 